\title{
Pollen Germination, Pollen Tube Growth and Crossability Studies in Wheat-Rye Crosses
}

\author{
P. N. Jagadev ${ }^{1 *}$ and V. K. Khanna ${ }^{2}$ \\ ${ }^{1}$ Department of Plant Breeding and Genetics, Odisha University of Agriculture and \\ Technology, Bhubaneswar, India \\ ${ }^{2}$ Department of Genetics and Plant Breeding, G.B. Pant University of Agriculture and \\ Technology, Pantnagar, India \\ *Corresponding author
}

\section{A B S T R A C T}

K e y w o r d s
$\begin{aligned} & \text { Pollen fall, Pollen } \\ & \text { germination, Pollen } \\ & \text { tube growth, Seed } \\ & \text { set, Wheat, Rye }\end{aligned}$
Article Info
$\begin{aligned} & \text { Accepted: } \\ & \text { 14 November } 2020 \\ & \text { Available Online: } \\ & 10 \text { December } 2020\end{aligned}$

\section{Introduction}

Wide hybridization is considered to be a useful tool in the hands of a plant breeder for creating new species, gene transfer or induction of haploids. Rye (Secale cereale L.) has a number of agronomic traits that could be incorporated into wheat (Triticum aestivum L. em. Thell.), such as greater tolerance to drought, cold and acid soils, resistance to several diseases of wheat, higher lysine content, higher $\mathrm{P}$ and $\mathrm{Cu}$ uptake efficiency, large number of spikelets and longer grains
(Sethi, 1989). However, the inter-generic hybrids between wheat and rye are difficult to obtain due to impaired development of hybrid embryos and many other incompatibility factors like variation in pollen germination, rate of pollen tube growth in the pistil (Singh and Khanna, 1988) and abnormal pollen tubes (Kodali and Khanna, 1994). Two genes viz. $\mathrm{Kr}_{1}$ and $\mathrm{Kr}_{2}$, located on wheat chromosomes $5 \mathrm{~B}$ and $5 \mathrm{~A}$, respectively, were thought to inhibit the growth of rye pollen tubes at base of the style and in the ovary wall, when present in the dominant form (Riley and 
Chapman, 1967). The present investigation was, therefore, undertaken to study the pollen fall, pollen germination and pollen tube growth behaviour in the inter-generic crosses of wheat and rye to determine if any abnormality in these was the cause of reduced crossability.

\section{Materials and Methods}

The experimental material consisted of five genotypes of hexaploid wheat viz., Chinese Spring $\left(\mathrm{kr}_{1} \mathrm{kr}_{1} \mathrm{kr}_{2} \mathrm{kr}_{2}\right)$, Hope $\left(\mathrm{Kr}_{1} \mathrm{Kr}_{1} \mathrm{Kr}_{2} \mathrm{Kr}_{2}\right)$, Highbury $\left(\mathrm{Kr}_{1} \mathrm{Kr}_{1} \mathrm{Kr}_{2} \mathrm{Kr}_{2}\right), \quad$ CS/Hope 5B $\left(\mathrm{Kr}_{1} \mathrm{Kr}_{1} \mathrm{kr}_{2} \mathrm{kr}_{2}\right.$ ), UP 2338 (unknown genes), a genotype of tetraploid wheat with unknown genes (WH 896) and two genotypes of diploid rye (Rye 8461 and Russian rye). The seeds were sown on two different dates during December. Emasculation of female parents (wheat) was done during March in the morning and evening hours on randomly selected plants when anthers were still pale green and two days later, when the stigmas became feathery and receptive, the pollinations were performed by hand pollinating the pistils with dusting ofpollens from dehiscing anthers of the male parents (rye). The pistils were then collected at 10 minutes, 30 minutes and 4 hours after pollination and fixed in 1:2 lacto-alcohol for at least 24 hours and then preserved in 70 per cent alcohol until further use. A few crossed spikes were also left in the plant to record the per cent seed set at maturity.

Five styles were chosen at random from each spike and all the pollen grains on the stigma were observed for pollen fall and pollen germination. These pistils were washed in distilled water and stained with cotton blue solution (D'Souza, 1972). The rate of pollen tube growth was measured with a micrometer and the length of only three longest pollen tubes was taken. Pollen tubes which were swollen at the tip or with more than one or two pollen tubes coming out from the same germ pore or which burst at the tip or twisted, were considered as abnormal. The mean data were then subjected to statistical analysis (Singh and Chaudhary, 1985).

\section{Results and Discussion}

Seed is formed by the fusion of male and female gametes and fertilization is made effective by the pollination of pistil. Amongst the many pre-fertilization processes, variation in pollen tube growth rates in the pistil was more frequently cited as the reason for lack of fertilization and hence might result in poor seed set (Selvanathan and Khanna, 1991). The development of pollen tube including abnormalities present, if any, should be equally emphasized for complete understanding of all the pre-zygotic gametophytic competition in flowering plants (Kodali and Khanna, 1994).

\section{Pollen fall}

The total pollen fall on different stigmas at various time intervals showed much differences (Table 1). The maximum pollen fall was recorded on selfing of UP 2338 at $4 \mathrm{~h}$ of pollination (102.3), whereas the lowest was recorded in WH 896 x Russian rye (39.0). In general, the pollen fall seemed to have a direct correlation with seed set, but the trend of pollen fall did not show differences between selfings and crosses as the mean pollen fall in CS selfing was high (71.9) (Fig. 1A) with 74.8 per cent seed set and it was comparable to the cross of the low crossable CS/Hope 5B with Rye 8461 having mean pollen fall (69.3) resulting in 13 per cent seed set. In the cross of low crossable cv. Hope with Rye 8461, although there was no seed set, still the pollen fall was high and comparable with CS crosses at same time intervals. 
Table.1 Pollen fall, pollen germination, pollen tube growth and abnormal pollen tubes at various intervals after pollination and seed set in different wheat-rye crosses and selfings

\begin{tabular}{|c|c|c|c|c|c|c|c|c|c|c|c|c|c|c|c|c|c|c|}
\hline \multirow[t]{2}{*}{ Cross } & \multicolumn{4}{|c|}{ Pollen fall } & \multicolumn{4}{|c|}{ Pollen germination $(\%)$} & \multicolumn{4}{|c|}{ Pollen tube growth $(\mu \mathrm{m})$} & \multicolumn{4}{|c|}{ Abnormal pollen tubes } & \multirow{2}{*}{$\begin{array}{c}\text { Seed } \\
\text { set } \\
(\%)\end{array}$} & \multirow{2}{*}{$\begin{array}{c}\text { Hybrid seed } \\
\text { germination } \\
(\%)\end{array}$} \\
\hline & $10 \mathrm{~min}$. & $30 \mathrm{~min}$. & 4h. & Mean & $10 \mathrm{~min}$. & $30 \mathrm{~min}$. & 4h. & Mean & 10 min. & $30 \mathrm{~min}$. & 4h. & Mean & $\begin{array}{c}10 \\
\text { min. }\end{array}$ & $\begin{array}{c}30 \\
\text { min. }\end{array}$ & $4 h$. & Mean & & \\
\hline \multirow{3}{*}{$\begin{array}{l}\text { CS (Selfed) } \\
\text { x Rye 8461 } \\
\text { x Russian rye }\end{array}$} & $39.3 \pm 0.9$ & $78.3 \pm 1.5$ & $98.0 \pm 2.3$ & $71.9 \pm 8.7$ & $39.3 \pm 2.0$ & $57.2 \pm 0.9$ & $65.3 \pm 2.5$ & $53.9 \pm 4.0$ & $51.3 \pm 3.7$ & $91.7 \pm 3.7$ & $205.3 \pm 7.3$ & $116.1 \pm 23.2$ & 0.0 & 0.0 & $5.9 \pm 3.2$ & $2.0 \pm 1.4$ & 74.8 & 89.8 \\
\hline & $33.0 \pm 1.5$ & $58.0 \pm 1.0$ & $77.7 \pm 2.3$ & $56.2 \pm 6.5$ & $51.9 \pm 1.1$ & $58.6 \pm 4.6$ & $69.7 \pm 3.3$ & $60.1 \pm 3.1$ & $40.3 \pm 3.7$ & $66.0 \pm 6.4$ & $165.0 \pm 11.0$ & $90.4 \pm 19.4$ & 0.0 & $4.1 \pm 2.1$ & $4.8 \pm 2.4$ & $2.9 \pm 1.2$ & 50.0 & 0.0 \\
\hline & $26.3 \pm 1.2$ & $53.3 \pm 0.3$ & $70.7 \pm 4.7$ & $50.1 \pm 6.6$ & $48.3 \pm 0.8$ & $59.7 \pm 4.4$ & $70.1 \pm 4.4$ & $59.4 \pm 3.6$ & $36.7 \pm 3.7$ & $73.3 \pm 7.3$ & $154.0 \pm 11.0$ & $88.0 \pm 17.8$ & 0.0 & $5.8 \pm 3.6$ & $5.7 \pm 0.4$ & $3.9 \pm 1.4$ & 53.3 & 0.0 \\
\hline \multirow{3}{*}{$\begin{array}{l}\text { CS/Hope } \\
\text { 5B(selfed) } \\
\text { x Rye 8461 } \\
x \text { Russian rye }\end{array}$} & $22.7 \pm 1.2$ & $52.3 \pm 1.5$ & $70.3 \pm 3.0$ & $48.4 \pm 7.0$ & $54.9 \pm 5.9$ & $58.9 \pm 3.4$ & $69.9 \pm 5.1$ & $61.2 \pm 3.3$ & $44.0 \pm 6.4$ & $106.3 \pm 3.7$ & $187.0 \pm 6.4$ & $112.4 \pm 20.9$ & 0.0 & $3.0 \pm 1.5$ & $5.2 \pm 2.6$ & $2.7 \pm 1.2$ & 68.1 & 77.4 \\
\hline & $30.7 \pm 1.8$ & $79.7 \pm 0.9$ & $97.7 \pm 1.7$ & $69.3 \pm 10.0$ & $60.5 \pm 6.2$ & $66.3 \pm 1.7$ & $72.9 \pm 1.5$ & $66.6 \pm 2.6$ & $36.7 \pm 3.7$ & $69.7 \pm 3.7$ & $95.3 \pm 3.7$ & $67.2 \pm 8.7$ & $4.3 \pm 2.2$ & 0.0 & $7.1 \pm 1.5$ & $3.8 \pm 1.3$ & 13.0 & 71.4 \\
\hline & $24.7 \pm 0.7$ & $62.7 \pm 1.8$ & $80.3 \pm 1.9$ & $55.9 \pm 8.3$ & $52.9 \pm 4.9$ & $66.7 \pm 0.4$ & $73.6 \pm 3.6$ & $64.4 \pm 3.5$ & $33.0 \pm 6.4$ & $62.3 \pm 3.7$ & $91.7 \pm 3.7$ & $62.3 \pm 8.8$ & $5.2 \pm 2.6$ & $4.4 \pm 2.4$ & $7.8 \pm 4.0$ & $5.8 \pm 1.6$ & 13.3 & 0.0 \\
\hline \multirow{3}{*}{$\begin{array}{l}\text { Hope (selfed) } \\
\text { x Rye } 8461 \\
\text { x Russian rye }\end{array}$} & $31.7 \pm 1.2$ & $53.3 \pm 2.0$ & $69.7 \pm 1.5$ & $51.5 \pm 5.6$ & $38.2 \pm 1.0$ & $56.6 \pm 0.3$ & $61.0 \pm 2.0$ & $51.9 \pm 3.6$ & $47.7 \pm 3.7$ & $102.7 \pm 3.7$ & $165.0 \pm 6.4$ & $105.1 \pm 17.1$ & 0.0 & $4.2 \pm 2.3$ & $4.1 \pm 2.1$ & $2.8 \pm 1.1$ & 68.3 & 80.1 \\
\hline & $23.7 \pm 2.0$ & $62.0 \pm 2.9$ & $79.3 \pm 1.8$ & $55.0 \pm 8.3$ & $50.6 \pm 5.3$ & $61.3 \pm 1.4$ & $67.5 \pm 3.0$ & $59.8 \pm 3.1$ & $14.7 \pm 3.7$ & $55.0 \pm 6.4$ & $77.0 \pm 6.4$ & $48.9 \pm 9.5$ & $6.1 \pm 3.1$ & $6.5 \pm 1.8$ & $10.2 \pm 1.4$ & $7.6 \pm 1.3$ & 0.0 & 0.0 \\
\hline & $19.3 \pm 0.7$ & $57.0 \pm 3.2$ & $75.3 \pm 1.8$ & $50.6 \pm 8.3$ & $48.3 \pm 4.4$ & $60.2 \pm 3.0$ & $48.0 \pm 1.2$ & $52.2 \pm 2.6$ & $22.0 \pm 6.4$ & $80.7 \pm 7.3$ & $91.7 \pm 3.7$ & $64.8 \pm 11.2$ & $7.0 \pm 3.6$ & $5.1 \pm 2.7$ & $6.0 \pm 0.6$ & $6.0 \pm 1.3$ & 3.7 & 50.0 \\
\hline \multirow{3}{*}{$\begin{array}{l}\text { Highbury } \\
\text { (selfed) } \\
\text { x Rye } 8461 \\
\text { x Russian rye }\end{array}$} & $25.0 \pm 2.3$ & $41.0 \pm 0.6$ & $61.3 \pm 0.9$ & $42.4 \pm 5.3$ & $35.5 \pm 4.3$ & $57.0 \pm 0.6$ & $61.7 \pm 2.5$ & $51.4 \pm 4.3$ & $36.7 \pm 3.7$ & $110.0 \pm 6.4$ & $172.3 \pm 3.7$ & $106.3 \pm 19.7$ & $7.0 \pm 3.5$ & $3.9 \pm 2.0$ & $5.7 \pm 3.0$ & $5.5 \pm 1.5$ & 56.7 & 77.0 \\
\hline & $17.0 \pm 0.6$ & $41.7 \pm 2.2$ & $53.3 \pm 2.9$ & $37.3 \pm 5.5$ & $25.5 \pm 2.1$ & $56.6 \pm 5.1$ & $68.3 \pm 1.9$ & $50.1 \pm 6.6$ & 0.0 & $58.7 \pm 3.7$ & $80.7 \pm 3.7$ & $46.4 \pm 12.1$ & 0.0 & $5.7 \pm 3.2$ & $8.0 \pm 2.7$ & $4.5 \pm 1.7$ & 0.0 & 0.0 \\
\hline & $18.3 \pm 0.9$ & $45.3 \pm 1.8$ & $56.7 \pm 1.9$ & $40.1 \pm 5.7$ & 0.0 & $54.0 \pm 5.8$ & $52.7 \pm 1.2$ & $35.6 \pm 9.1$ & $25.7 \pm 3.7$ & $66.0 \pm 11.0$ & $84.3 \pm 3.7$ & $58.7 \pm 9.4$ & 0.0 & $3.5 \pm 1.8$ & $8.1 \pm 2.3$ & $3.9 \pm 1.4$ & 5.4 & 50.0 \\
\hline \multirow{3}{*}{$\begin{array}{l}\text { UP } 2338 \\
\text { (selfed) } \\
\text { x Rye 8461 } \\
\text { x Russian rye }\end{array}$} & $29.3 \pm 1.2$ & $77.7 \pm 1.9$ & $102.3 \pm 1.5$ & $69.8 \pm 10.8$ & $37.9 \pm 3.4$ & $51.8 \pm 1.0$ & $62.3 \pm 2.4$ & $50.7 \pm 3.7$ & $25.7 \pm 3.7$ & $117.3 \pm 3.7$ & $165.0 \pm 16.8$ & $102.7 \pm 21.1$ & 0.0 & $4.0 \pm 2.0$ & $4.0 \pm 2.1$ & $2.7 \pm 1.1$ & 67.5 & 82.0 \\
\hline & $10.7 \pm 0.7$ & $29.0 \pm 1.0$ & $50.0 \pm 2.1$ & $29.9 \pm 5.7$ & $31.7 \pm 4.4$ & $41.7 \pm 0.9$ & $76.0 \pm 1.2$ & $49.8 \pm 6.9$ & $18.3 \pm 3.7$ & $51.3 \pm 7.3$ & $88.0 \pm 6.4$ & $52.5 \pm 10.5$ & 0.0 & $6.4 \pm 3.2$ & $8.1 \pm 1.2$ & $4.8 \pm 1.6$ & 10.0 & 75.0 \\
\hline & $23.7 \pm 1.2$ & $33.7 \pm 0.9$ & $46.3 \pm 0.3$ & $34.5 \pm 3.3$ & $33.8 \pm 1.8$ & $53.7 \pm 2.4$ & $67.3 \pm 2.1$ & $51.6 \pm 5.0$ & $25.7 \pm 3.7$ & $51.3 \pm 3.7$ & $69.7 \pm 3.7$ & $45.2 \pm 8.3$ & 0.0 & $4.3 \pm 2.2$ & $8.2 \pm 1.8$ & $4.2 \pm 1.4$ & 0.0 & 0.0 \\
\hline \multirow{3}{*}{$\begin{array}{l}\text { WH 896 } \\
\text { (selfed) } \\
\text { x Rye } 8461 \\
\text { x Russian rye }\end{array}$} & $22.0 \pm 1.0$ & $41.3 \pm 0.9$ & $52.3 \pm 1.2$ & $38.6 \pm 4.5$ & 0.0 & $54.7 \pm 2.9$ & $68.0 \pm 4.1$ & $40.9 \pm 10.5$ & 0.0 & $95.3 \pm 7.3$ & $176.0 \pm 6.4$ & $90.4 \pm 25.6$ & 0.0 & $5.2 \pm 2.9$ & $6.8 \pm 1.4$ & $4.0 \pm 1.4$ & 54.4 & 72.6 \\
\hline & $23.3 \pm 1.8$ & $39.3 \pm 2.0$ & $41.7 \pm 0.9$ & $34.8 \pm 3.0$ & $34.6 \pm 2.6$ & $50.9 \pm 4.8$ & $67.8 \pm 1.4$ & $51.1 \pm 5.1$ & $29.3 \pm 3.7$ & $58.7 \pm 9.7$ & $102.7 \pm 3.7$ & $63.5 \pm 11.1$ & $8.9 \pm 4.5$ & $3.8 \pm 1.9$ & $6.8 \pm 0.2$ & $6.5 \pm 1.6$ & 25.0 & 0.0 \\
\hline & $17.0 \pm 1.2$ & $33.7 \pm 1.9$ & $39.0 \pm 2.9$ & $29.9 \pm 3.5$ & $30.4 \pm 1.5$ & $54.1 \pm 0.7$ & $62.4 \pm 2.6$ & $49.0 \pm 4.9$ & $44.0 \pm 6.4$ & $77.0 \pm 6.4$ & $121.0 \pm 6.4$ & $80.7 \pm 11.6$ & $7.9 \pm 4.0$ & $7.5 \pm 3.8$ & $8.0 \pm 1.2$ & $7.8 \pm 1.6$ & 0.0 & 0.0 \\
\hline \multirow{2}{*}{$\begin{array}{l}\text { Rye } 8461 \\
\text { (selfed) Russian } \\
\text { rye (selfed) }\end{array}$} & $28.3 \pm 2.0$ & $52.7 \pm 1.3$ & $69.7 \pm 2.4$ & $50.2 \pm 6.1$ & $36.3 \pm 2.2$ & $46.1 \pm 1.9$ & $76.8 \pm 2.0$ & $53.1 \pm 6.2$ & $47.7 \pm 3.7$ & $106.3 \pm 14.7$ & $223.7 \pm 3.7$ & $125.9 \pm 26.3$ & 0.0 & $6.1 \pm 3.1$ & $9.5 \pm 1.5$ & $5.2 \pm 1.7$ & 61.6 & 83.4 \\
\hline & $37.0 \pm 1.7$ & $47.3 \pm 2.7$ & $66.0 \pm 2.1$ & $50.1 \pm 4.4$ & $34.9 \pm 2.5$ & $52.7 \pm 2.0$ & $66.5 \pm 4.2$ & $51.4 \pm 4.8$ & $55.0 \pm 6.4$ & $91.7 \pm 7.3$ & $212.7 \pm 3.7$ & $119.8 \pm 24.0$ & $4.9 \pm 2.5$ & 0.0 & $4.9 \pm 2.5$ & $3.2 \pm 1.3$ & 55.6 & 75.1 \\
\hline
\end{tabular}

Table.2 Correlation studies for cross ability characters in wheat and rye

\begin{tabular}{|l|c|c|c|c|}
\hline Character & $\begin{array}{c}\text { Pollen } \\
\text { germination }\end{array}$ & $\begin{array}{c}\text { Pollen tube } \\
\text { growth }\end{array}$ & $\begin{array}{c}\text { Abnormal } \\
\text { pollen tubes }\end{array}$ & Seed set \\
\hline Pollen fall & $0.53^{*}$ & 0.39 & -0.42 & $0.48^{*}$ \\
\hline Pollen germination & & 0.04 & 0.04 & 0.07 \\
\hline Pollen tube growth & & & $-0.63^{* *}$ & $0.91^{* *}$ \\
\hline Abnormal pollen tubes & & & & $-0.65^{* *}$ \\
\hline
\end{tabular}

*, ** Significant at $5 \%$ and $1 \%$ level, respectively 
Fig.1 Pollen tube studies in wheat-rye crosses and wheat selfings: (A) High pollen fall in Chinese Spring (CS) on selfing at 4 hrs. after pollination (100x); (B) Pollen grains showing germination and sterile pollen grains in CS/Hope 5B x Rye 8461 at $10 \mathrm{~min}$. after pollination (100x);(C) A swollen tip of pollen tube in CS x Russian rye at 30 min. after pollination (400x); (D) Pollen tube growth on the surface of the stylar branch in CS/Hope 5B on selfing at 4 hrs. after pollination (200x);(E) Two pollen tubes coming out of a pollen grain in Highbury $x$ Rye 8461 at 4 hrs. after pollination (200x); (F) An abnormal pollen tube growing in the wrong direction in UP2338 x Russian rye at 30 min. after pollination (400x); (G) An abnormal pollen tube showing coiling before entering into the stylar hair in CS/Hope 5B x Russian rye at 30 min. after pollination (400x); (H) A coiled pollen tube in CS x Rye 8461 at 4 hrs. after pollination (200x); (I) A twisted pollen tube in WH 896 x Russian rye at 30 min. after pollination (400x); (J) Hybrid seeds set in CS/Hope 5B x Rye 8461 at 22 days after pollination.
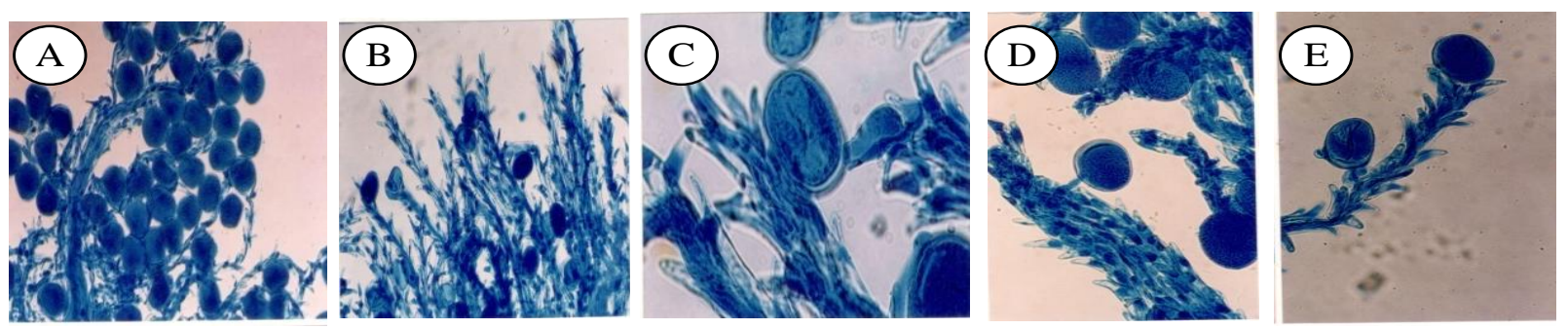

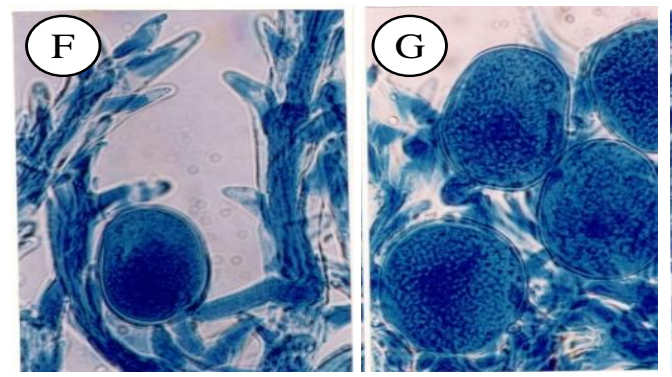

\section{Pollen germination}

Although the onset of pollen grain germination was variable in selfings and crosses, the majority of the pollen grains germinated within $10 \mathrm{~min}$. after pollination (Table 1). Maximum pollen germination after $10 \mathrm{~min}$. of pollination was recorded in CS/Hope 5B x Rye 8461 (60.5 per cent) (Fig.1B) and the least was in Highbury $x$ Rye 8461 (25.5 per cent). In general, the germination of pollen grains was found to be more in crosses than in the selfings except in a few cases. There seemed to be a constant increase in pollen germination from $10 \mathrm{~min}$. to $4 \mathrm{~h}$ after pollination. The mean per cent pollen germination did not show a direct correlation with seed set. In fact, the low crossable CS/Hope 5B had the highest mean pollen germination (66.6 per cent) compared to other genotypes when crossed with Rye 8461 having 13 per cent seed set. Selvanathan and Khannna (1989) also reported that inadequate pollination or low pollen germination seemed to be the cause of low seed set in rice.

\section{Pollen tube growth}

Because of the irregularity in pollen germination, the pollen tube growth was irregular (Table 1). At $10 \mathrm{~min}$. of pollination, 
a number of pollen grains had germinated and the tubes had penetrated into the stigma hairs. In WH 896 selfing and Highbury cross with Rye 8461 , there was no growth of the pollen tubes after $10 \mathrm{~min}$. The maximum pollen tube growth after $10 \mathrm{~min}$. of pollination was observed in Russian rye selfing $(55.0 \mu \mathrm{m})$ and the lowest in Hope x Rye $8461(14.7 \mu \mathrm{m})$. After 30 min. of pollination, there was greater differentiation and elongation of the tubes, whereas some had just started to grow and all intermediate stages were observed.

After $4 \mathrm{~h}$ of pollination, very long pollen tubes were observed. Since the styles were quite long, the pollen tubes could not be traced upto the base of the style as their staining became faint when they moved towards the ovary.

The highest pollen tube growth was observed in selfings of both the ryes and the least in UP $2338 \times$ Russian rye $(69.7 \mu \mathrm{m})$ after $4 \mathrm{~h}$ of pollination. It was observed that the rate of pollen tube growth in most of the crosses was fast at $4 \mathrm{~h}$ showing a considerable increase over a period of $3 \mathrm{~h}$ (between $30 \mathrm{~min}$ and 4 h). It was comparatively easy to record the pollen tube growth upto $4 \mathrm{~h}$ after pollination, but as the pollen tubes elongated into the stylar tissues, the quantification of rate of pollen tube growth by measuring the length, at longer time intervals proved much more difficult.

For $4 \mathrm{~h}$ also, the reliability of the length was established by working out the averages on a large number of pollen tubes. Considering the mean pollen tube growth, it seemed that the length of the pollen tubes had a direct correlation with seed set (Neeraj and Khanna, 1992) as the pollen tubes were quite long in selfings and the seed set were also quite good. Among the crosses with rye, CS had longer pollen tubes and the seed set was better than others.

\section{Abnormal pollen tubes}

On the abnormal behavior of the pollen tube growth studies, the occurrence of swelling of pollen tubes was observed (Fig. 1C). Swelling in pollen tube tip seemed to be filled with a dense cytoplasm and found to be occurred in the hairs of the style as well as in the transmitting tissues of the style. Many pistils showed no swellings at all, while others had one or two. Some showed pollen tube growth on the surface of the stylar branch (Fig. 1D) and some pollen grains were having more than one pollen tube growing into the stylar hairs (Fig. 1E). Rarely, other aberrations like pollen tubes growing in the wrong direction (Fig. 1F) or bursting of the pollen tube tip were observed. Some showed coiling while germinating (Fig. 1G and $1 \mathrm{H}$ ) and twisting in the stylar tissues (Fig.1I). The abnormalities were observed after 10 min. of pollination. The maximum abnormalities were observed after $4 \mathrm{~h}$ of pollination in Hope x Rye 8461 (10.2 per cent) having no seed set. In general, the frequencies of abnormalities were more in the crosses.

The occurrence of abnormalities did not seem to show any relation with cross ability as the mean abnormal pollen tubes was similar (3.9 per cent) in both the crosses of CS x Russian rye (53.3 per cent seed set) and Highbury $x$ Russian rye (5.4 per cent seed set). As reported, presence of abnormalities in the pollen tube growth, absence of fertilization (Lange and Wojciechowska, 1976; Jalani and Moss, 1980) or collapse of fertilized ovules (Bassiri et al., 1987) led to failure of seed formation.

\section{Seed set}

The number of florets pollinated and the per cent seed set in different crosses between wheat and rye and the selfed ones were given in Table 1. Seed set was found to be higher in 
the selfings of wheat and rye as compared to their hybrids under in vivo conditions. In the production of wheat-rye hybrids, there was a low rate of success. In general, CS showed a better seed set of 50.0 and 53.3 per cent in crosses with Rye 8461 and Russian rye, respectively. The substitution line, CS/Hope 5B gave a seed set of 13.0 and 13.3 per cent in crosses with Rye 8461 and Russian rye, respectively. The seed set obtained in cvs. Hope and Highbury was 3.7 and 5.4 per cent, respectively when crossed with Russian rye and there was no seed formation when crossed with Rye 8461. The tetraploid wheat cv. WH 896 gave a better seed set $(25.0 \%)$ than the hexaploid cv. UP 2338 (10.0\%) when crossed with Rye 8461, while no seed set was seen with Russian rye. Hence, it was observed that the cross abilities of exotic wheat were better with Russian rye, while it was so with Rye 8461 for indigenous wheat cultivars.

\section{Germination of $F_{1}$ seed}

As regards to germination of hybrid seeds, maximum germination was observed in the crosses of UP 2338 (75.0 per cent) followed by $\mathrm{CS} /$ Hope $5 \mathrm{~B}$ (71.4 per cent) with Rye 8461, while it was 50 per cent in the crosses of Highbury and Hope with Russian rye (Table 1). However, there was no germination of hybrid seeds in other crosses.

\section{Correlation studies for crossability}

Correlation coefficients were estimated for different pre-fertilization characters and seed set in wheat-rye crosses and selfings (Table 2). Seed set showed a highly significant positive correlation with average pollen fall (0.45) and pollen tube growth (0.91), while a highly significant negative correlation was observed with pollen tube abnormalities (0.65). Among the pre-fertilization characters, average pollen fall showed a highly significant positive correlation with pollen germination (0.53) and a negative correlation with abnormal pollen tubes (-0.43). A highly significant negative correlation $(-0.63)$ was also observed between pollen tube growth and abnormal pollen tubes. Kodali and Khanna (1994) also reported a positive correlation between pollen tube length and seed set in wheat-barley crosses.

\section{Seed set and cross ability genes}

In the present study, the seed set varied from 0.0 to 53.3 per cent in the crosses was clearly related to cross ability genes. The seed set was the highest when CS (with homozygous recessive $\mathrm{kr}_{1}$ and $\mathrm{kr}_{2}$ genes) was crossed with Rye 8461 and Russian rye, but upto 13.3 per cent in the crosses of substitution line CS/Hope 5B (having dominant homozygous $\mathrm{Kr}_{1}$ ) with the rye genotypes and the seed set was nil or very less when Highbury and Hope (having dominant homozygous $\mathrm{Kr}_{1}$ and $\mathrm{Kr}_{2}$ ) were crossed with the rye genotypes (Table 1). Hence, our study showed that the activity of the $\mathrm{Kr}_{1}$ and $\mathrm{Kr}_{2}$ genes manifested itself in a slow-down of the rate of pollen tube growth of rye in the pistils of wheat and an increase in the number of abnormal pollen tubes in wheat-rye crosses. Kour et al., (2009) also reported that high pollen germination and pollen tube growth resulted in high rates of seed and embryo formation. Hence, a wheat genotype with high average pollen fall and longer pollen tubes having least abnormalities was likely to set more seeds if crossed with a rye genotype.

\section{References}

Bassiri, A., Ahmed, F. and Slinkard, A.E. 1987. Pollen grain germination and pollen tube growth following in vivo and in vitro self and interspecific pollinations in annual Cicer species. Euphytica.36: 667-675. 
D’Souza, L. 1972. Staining pollen tubes in styles of cereals with cotton blue: fixation by ethano-lactic acid for enhanced differentiation. Stain Tech. 47: 107-108.

Jalani, B. S. and Moss, J.P. 1980. The site of action of the crossability genes $\left(\mathrm{Kr}_{1}, \mathrm{Kr}_{2}\right)$ between Triticum and Secale. I. Pollen germination, pollen tube growth and the number of pollen tubes. Euphytica.29: 571-579.

Kodali, S. and Khanna, V.K. 1994. Standardization of the best timing of growth hormone application in wheatbarley crosses to increase seed set. Cereal Res. Coтmu.22: 309-313.

Kour, A., Bhatt, U. and Khanna,V.K. 2009. Study of pre-fertilization parameters in wheat-maize crosses. Indian J. Genet. 69: 87-92.

Lange, W. and Wojciechowska, B. 1976. The crossing of common wheat (Triticum aestivum L.) with cultivated rye (Secalecereale L.). I. Crossability, pollen grain germination and pollen tube growth. Euphytica.25: 609-620.

Neeraj and Khanna, V.K. 1992. Studies on pollen germination, pollen tube growth and seed set in reciprocal wheat-barley crosses. Wheat Inform. Serv. 74: 2832.

Riley, R. and Chapman, V. 1967. The inheritance of wheat crossability with rye. Genet. Res. 9: 259-267.

Selvanathan, M. and Khanna, V.K. 1991. Studies on meiosis, pollen grain germination, pollen tube growth and crossability between different varieties of rice (Oryza sativa). Cereal Res. Сотти. 19: 351-355.

Selvanathan, M. and Khanna,V.K. 1989. Pollen development and hybridization between indica varieties of rice. Intl.Rice Res.Newsl. 14(4): 7-8.

Sethi, G.S.1989. Towards the introgression of rye genes into wheat. Rev. Adv. Pl.Biotech. pp.145-155.

Singh, M. and Khanna, V.K. 1988. Effect of gamma radiation on the crossability of wheat, triticale and rye and on meiosis, pollen grain germination and pollen tube growth. Cytologia. 53: 123-130.

Singh,R.K.and Chaudhary, B.D. 1985. Elementary statistics. In: Biometrical Methods in Quantitative Genetic Analysis. Kalyani Publ., New Delhi.pp.19-38.

\section{How to cite this article:}

Jagadev, P. N. and Khanna, V. K. 2020. Pollen Germination, Pollen Tube Growth and Crossability Studies in Wheat-Rye Crosses. Int.J.Curr.Microbiol.App.Sci. 9(12): 1921-1927. doi: https://doi.org/10.20546/ijcmas.2020.912.228 